\title{
APRENDIENDO DE LA NATURALEZA DESDE LOS SISTEMAS
}

Vedoya, Daniel

Instituto de Investigaciones Tecnológicas para el Diseño Ambiental del hábitat Humano (ITDAHu). Facultad de Arquitectura y Urbanismo - Universidad Nacional del Nordeste (FAU - UNNE). Av. Las Heras No 727 - 3500 - Resistencia - Provincia del Chaco - República Argentina. Tel.+54 03624420 088. E-mail: devedova@gmail.com

"La filosofía [natural] está escrita en ese grandioso libro que tenemos abierto ante los ojos, (quiero decir, el universo), pero no se puede entender si antes no se aprende a entender la lengua, a conocer los caracteres en los que está escrito. Está escrito en lengua matemática y sus caracteres son triángulos, círculos y otras figuras geométricas, sin las cuales es imposible entender ni una palabra; sin ellos es como girar vanamente en un oscuro laberinto." (Galileo Galilei, 1592)

Las matemáticas no son un descubrimiento del genio humano. El hombre tan sólo constató su existencia en un sistema natural donde reinaba el orden, el ritmo y la proporción, y sintió la necesidad de crear una simbología adecuada que le permitiera interpretar, comprender y aplicar el conocimiento matemático.

A continuación veremos un conjunto de esos conocimientos que, a priori, nos permitirá adentrarnos en el estudio de la naturaleza desde un enfoque sistémico, en el que abundan situaciones sorprendentes e insospechadas.

\section{Los números primos}

Los números primos son un caso particular en la familia de los números naturales que só0lo son múltiplos de sí mismos y de la unidad. El único número primo par es el 2. Los demás todos son impares.

Otra característica de esta familia de números es que, hasta la fecha, no se ha logrado enunciar ninguna fórmula capaz de determinar cómo obtener un número primo. Se sabe que existen en un entorno que va siguiendo los múltiplos de $6+/$ - 1, pero su aparición sigue siendo espontánea, lo que significa que no todos los números que se encuentran en ese entorno sean necesariamente primos.

Euclides demostró que hay infinitos números primos, por lo que siempre habrá un número primo mayor que el denominado mayor primo conocido.

A medida que avanza el tiempo y se cuenta con nuevos métodos de cálculo, siguen descubriéndose números primos, siendo $2^{77232917}$ - 1 el más grande conocido hasta la fecha, descubierto en 2017 y cuenta con 23.249.425 dígitos.

Quizá la pregunta apropiada sería ¿tienen los números primos alguna injerencia en la vida común de los seres humanos para que su estudio tenga alguna trascendencia?

Una aplicación directa de los números primos que tiene un significativo valor en las actividades cotidianas es el encriptamiento de los códigos que protegen las tarjetas de crédito.

Para garantizar la seguridad en el intercambio de información en la web se utiliza un algoritmo criptográfico desarrollado en 1977 por Rivest, Shamir y Adleman, del Instituto Tecnológico de Massachusetts (MIT), identificado por las siglas de sus apellidos (RSA).

Este algoritmo está basado la factorización de números enteros en números primos, siguiendo la rutina de todo sistema criptográfico de clave pública: el usuario posee dos claves de cifrado, una pública y otra privada. Al enviar un mensaje, el emisor utiliza la clave pública del receptor, cifrando de este modo su mensaje. El receptor, al recibir el mensaje, lo descifra aplicando su clave privada.

El sistema RSA consiste en representar los mensajes enviados mediante números enteros construidos a partir del producto de dos números primos muy grandes elegidos al azar, mantenidos en secreto.

Aunque pareciera muy fácil descubrir el código, lo que se lograría descomponiendo el número entero en sus factores primos, no lo es en este caso, pues se trabaja con números primos de 100 dígitos 
que, al multiplicarlos, dan como resultado un número de tal magnitud que descomponerlo representa una tarea prácticamente imposible.

Es así que los números primos resultan muy importantes para los negocios, las comunicaciones, los registros, etc., pues todas las transacciones comerciales que se realizan por Internet dependen de ellos.

Hasta la fecha, conocer cómo se distribuyen, cómo se pueden obtener números primos cada vez más grandes, que puedan ser utilizados como clave criptográfica, sigue siendo el reto permanente para las tecnologías y para las propias matemáticas.

Un desafío que plantea la famosa hipótesis de Riemann, que hasta ahora nadie ha sido capaz de resolver, pese al esfuerzo de los mejores matemáticos del mundo durante 159 años. Hipótesis planteada en 1859 por Bernhard Reinmann, que trata de explicar cómo podrían estar distribuidos los números primos, pero que su autor no pudo llegar a demostrarla. Si en algún momento alguien lograra hacerlo, esto complicaría la forma de hacer negocios y sin duda llegaría a afectar el futuro de la computación.

A tal punto que, en 2000, el Instituto Clay de Matemática, de la Universidad de Cambridge (Massachussets) ha ofrecido un premio de un millón de dólares a quien lograra demostrar esa famosa conjetura.

\section{La proporción áurea}

"Se dice que una línea recta está dividida en el extremo y su proporcional cuando la línea entera es al segmento mayor como el mayor es al menor." (Euclides en "Los Elementos")

Este teorema, conocido vulgarmente como el de la media y extrema razón, se refiere a la división de un segmento en otros dos ( $\boldsymbol{a}$ y $\boldsymbol{b}$ ), tales que el segmento mayor (a) es proporcional al menor $(\boldsymbol{b})$, de la misma manera que el segmento total $(\boldsymbol{a}+\boldsymbol{b})$ lo es al segmento mayor $(\boldsymbol{a})$.

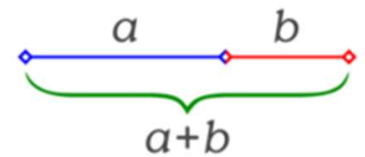

$$
x^{2}-x-1=0
$$

$$
\frac{a+b}{a}=\frac{a}{b} \quad \frac{x+1}{x}=\frac{x}{1}
$$

$$
x+1=x^{2}
$$$$
x=\frac{1 \pm \sqrt{5}}{2}
$$

El valor de esta proporción es un número irracional denominado phi $(\Phi)^{3}$, conocido como el "número de oro", cuyas características y propiedades son muy interesantes:

$$
x=\frac{1+\sqrt{5}}{2}=1,61803 \ldots=\varphi \quad x=\frac{1-\sqrt{5}}{2}=-0,61803 \ldots=-\frac{1}{\varphi}
$$

Una de esas propiedades es la conformación de una serie, conocida como "serie dorada", en la que cada número de la misma es el resultado de sumar los dos anteriores:

$\Phi^{-4}=0,14589803375 \ldots=\Phi^{-6}+\Phi^{\square 5}$

$\Phi^{-3}=0,23606797750 \ldots=\Phi^{-5}+\Phi^{-4}$

$\Phi^{-2}=0,38196601125 \ldots=\Phi^{-4}+\Phi^{-3}$

$\Phi^{-1}=0,61803398875 \ldots=\Phi^{-3}+\Phi^{-2}$

$\Phi^{0}=1=\Phi^{-2}+\Phi^{-1}$

$\Phi=1,61803398875 \ldots=\Phi^{-1}+\Phi^{0}$

$\Phi^{2}=2,61803398875 \ldots=\Phi^{0}+\Phi$

$\Phi^{3}=4,23606797750 \ldots=\Phi+\Phi^{2}$

$\Phi^{4}=6,85410196625 \ldots=\Phi^{2}+\Phi^{3}$

Construyendo un rectángulo de base $\Phi$ y altura 1, que llamaremos "rectángulo áureo", podemos ir construyendo nuevos rectángulos áureos de dimensión menor, procediendo de la siguiente manera:

\footnotetext{
${ }^{3}$ Se aplica la letra phi al nombre del número de oro en homenaje a Fidias, el más famoso escultor de la antigua Grecia, por ser la inicial de su nombre.
} 
Tomando el lado menor del rectángulo, construimos un cuadrado de modo de dividirlo en éste y un nuevo rectángulo, que ahora tendrá como lado mayor el que antes fuera lado menor del rectángulo inicial, y como lado menor, el segmento que resulte de restar al lado mayor del rectángulo inicial, su lado menor. Siguiendo sucesivamente este procedimiento hacia el interior del rectángulo áureo inicial, obtendremos como resultado el que se indica en la figura, en la que además hemos trazado una espiral que llamaremos "espiral dorada".

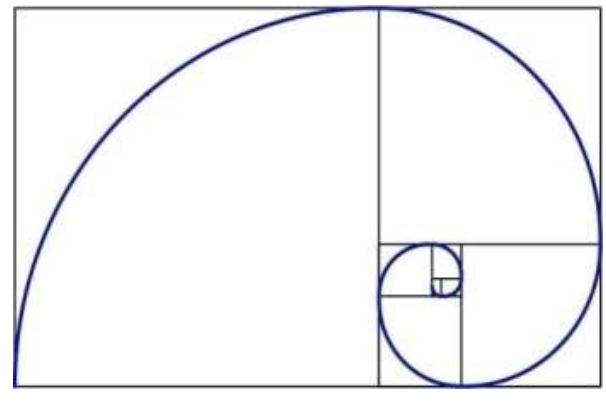

Espiral dorada. Fuente: producción propia

Esta singular espiral no sólo representa una de las curiosidades de la proporción áurea, sino que además es el proceso de crecimiento armónico de los moluscos gasterópodos provistos de una concha espiral, como el Nautilus Shell.
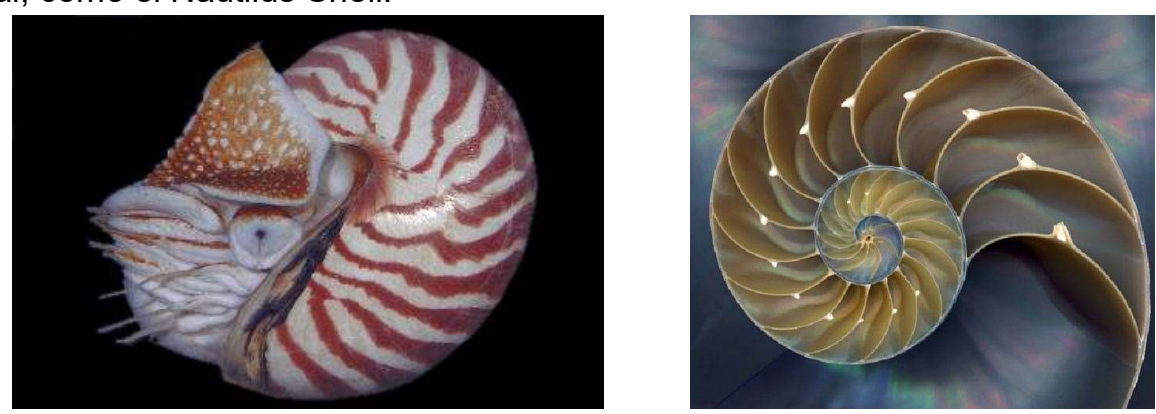

Nautilus Shell. Fuente: http://www.tokaji-sika.com/blog/91.htm/

\section{La serie de Fibonacci}

Leonardo de Pisa, más conocido como Fibonacci, preocupado por la descendencia de una pareja de conejos y de qué modo esta descendencia podría ir creciendo, estudió lo que pasaría si esta evolución se producía con una frecuencia determinada, descubriendo que existe un patrón cuyo resultado es una serie numérica, donde cualquier número perteneciente a la serie es consecuencia de la suma de sus dos precedentes:

$1,1,2,3,5,8,13,21,34,55,89,144,233,577,810,1.387,2.197,3.584,5.781,9.365,15.146 \ldots$

Del mismo modo que en el caso del rectángulo áreo, podemos construir otro rectángulo siguiendo un procedimiento similar, pero en sentido inverso.

Tomando como base un cuadrado de lado 1 , le anexamos otro igual, obteniendo así un rectángulo de base 2 y altura 1 . Adjunto a este rectángulo construimos un cuadrado de lado 2 , y obtenemos un nuevo rectángulo de base 3 y altura 2 . Ahora le anexamos un cuadrado de lado 3 , lo que da por resultado un nuevo rectángulo de base 5 y altura 3 . Continuando con este proceso, lo que iremos obteniendo serán rectángulos en los que sus lados pertenecen a algún par de la serie de Fibonacci, y uniendo los vértices de los rectángulos lograremos dibujar una espiral que, si la comparamos con la dorada comprobaremos que existe una similitud muy aproximada entre ambas. 


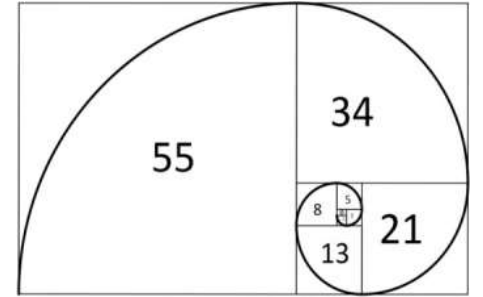

Espiral de Fibonacci

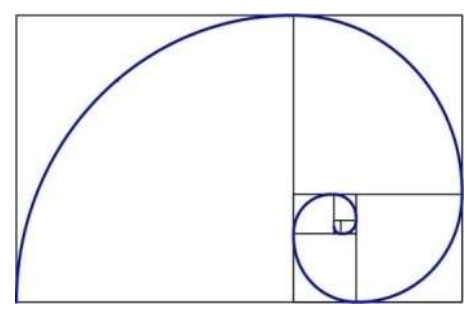

Espiral dorada

Obsérvese la similitud existente entre ambas curvas

Lo asombroso es que esta forma espiral también la encontramos en abundancia en la naturaleza, como en la distribución de los semillas en una flor del girasol o también en la Vía Láctea.

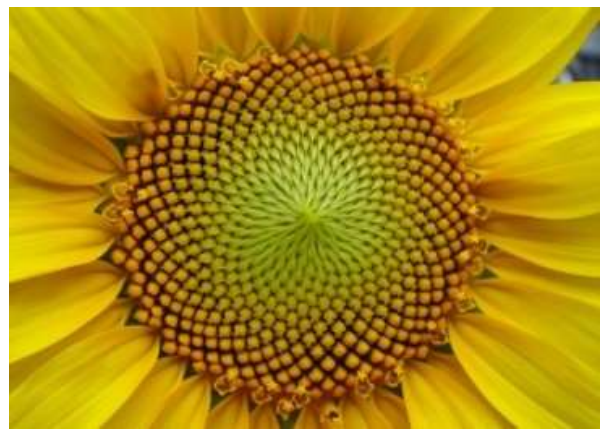

Flor del girasol

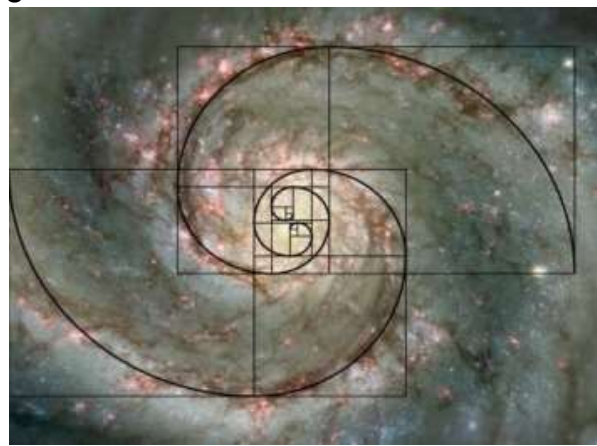

Una representación de la Vía Láctea

Además, si contamos las curvas en que se distribuyen las semillas de la flor, comprobaremos que su número, en un sentido, corresponde a uno de la serie de Fibonacci, y en el sentido contrario, al número siguiente.

\section{Los números trascendentes}

Se denomina "número transcendente" a todo número que no es algebraico, es decir, que no es solución de ninguna ecuación polinómica con coeficientes racionales.

Algunos ejemplos de números transcendentes son: $\pi$ y $\mathbf{e}$.

Es mucho lo que puede decirse de $\pi$, pero también es cierto que es harto conocido, de modo que nos limitaremos a sólo mencionarlo acá.

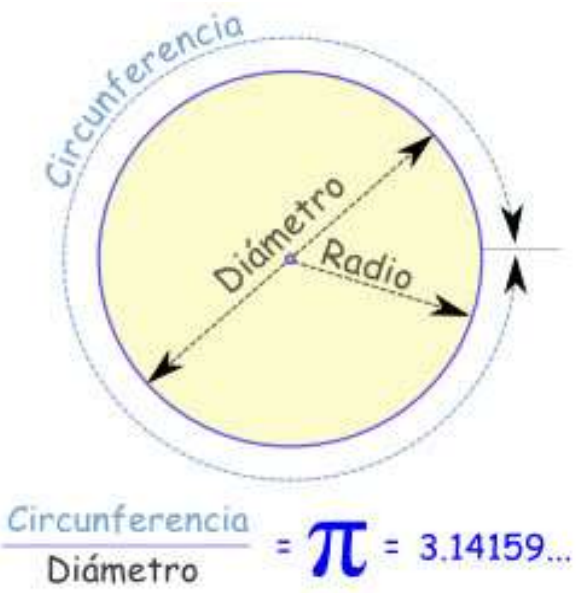

Aunque la lista es infinita, se dan acá los primero dígitos del valor de $\pi$

$$
\pi=3,1415926535897932384 \ldots
$$

Por su parte, e aparece en casi todas las ramas de la ciencia y de la tecnología, y también en algunas situaciones de la vida:

- en economía, en el interés continuo. 
- en química, en la desintegración radiactiva.

- en la naturaleza: en el crecimiento demográfico de una población.

- en arqueología para determinar la edad aproximada de cualquier objeto o fósil, mediante el carbono 14, C-14.

- en fenómenos con crecimiento y decrecimiento exponencial.

- en el crecimiento de una colonia de bacterias.

- en la absorción de los rayos X por la materia.

- en la ingesta de alcohol y conducción de vehículos.

Si bien la lista es infinita, se dan acá los primero dígitos del valor de e:

$$
\boldsymbol{e}=2,7182818284590452353 \ldots
$$

\section{Los números complejos}

Los números complejos son un invento de los matemáticos (un recurso) para resolver las ecuaciones correspondientes que no tienen ninguna solución real, resultan de la conjunción de un número real y uno imaginario y parten el número imaginario (i) del tipo:

$$
i=\sqrt{-1}
$$

En síntesis, los números complejos permiten representar situaciones de la realidad cuya descripción y tratamiento es posible gracias a sus propiedades:

- En el diseño de un ala de avión se logra una sección cuya forma permite que el aire fluya sin turbulencias.

- En el estudio de fractales.

- En áreas diversas de la ciencia y de la tecnología: comunicaciones, aeronáutica y astronáutica, diseño de circuitos, acústica, sismología, ingeniería biomédica, sistemas de generación y distribución de energía, control de procesos químicos y procesamiento de voz.

- Algunas magnitudes eléctricas de un circuito de corriente alterna se expresan utilizando la notación exponencial de los números complejos.

- En el movimiento ondulatorio, la amplitud de una onda armónica en función del tiempo es representada, en algunos casos, en notación compleja.

\section{Las matemáticas en la naturaleza}

Los panales de las abejas están formados por celdas hexagonales.

Desde siglos remotos se tiene la convicción de que no existe otra forma que no sea el hexágono que aproveche al máximo el espacio con un consumo mínimo de material.

No obstante, nunca nadie hubo podido decir por qué, hasta que en 1999 se logró demostrar matemáticamente y explicar sus ventajas en lo que se llamó la "conjetura del panal de abejas"4.

Las celdas hexagonales les permiten a las abejas aprovechar al máximo el espacio, construir un panal ligero y resistente con el mínimo de cera necesaria, y al mismo tiempo almacenar la mayor cantidad posible de miel.

Es así que se considere al panal una obra maestra de la arquitectura, y los diseñadores están imitando el panal para producir estructuras resistentes con un óptimo aprovechamiento del espacio.

En los genes de las abejas se ha mantenido latente, durante millones de años, el empleo de los hexágonos como las formas más eficaces para desarrollar sus panales.

Antes de pasar al siguiente tema, nos detendremos a analizar este caso particular del panal de las abejas.

El principio que rige la generación de tramas en el espacio bidimensional, partiendo de polígonos regulares, es la coincidencia angular en el punto de concurrencia de éstos, lo que significa que la

\footnotetext{
${ }^{4}$ La "conjetura del panal de abeja" lo fue hasta que se convirtió en un teorema matemático que sostiene que una red hexagonal en forma de panal de abeja es la mejor manera de dividir una superficie en regiones de igual área y con el mínimo perímetro total. Si bien la conjetura es atribuida a Pappus de Alejandría (c. 290 - 350 a. C.), el teorema fue demostrado por el matemático Thomas C. Hales (1999).
} 
suma de los ángulos interiores perimetrales pertenecientes a los polígonos concurrentes sea $360^{\circ}$ en el punto de concurrencia.

Esta condición la cumplen sólo tres polígonos regulares si se trata de lograr una coincidencia angular utilizando en cada caso un solo tipo de figura. Son ellos: el triángulo, el cuadrado y el hexágono. No obstante, hemos visto que la selección hecha por las abejas responde a un criterio de economía de la sustancia y para ello han adoptado la trama hexagonal.

Resulta aún más interesante este estudio cuando observamos no sólo cómo se ordenan las celdas entre sí, conformando una sumatoria organizada en un mismo plano, con sus caras orientadas hacia una dirección, sino cómo se imbrican por la parte opuesta con otra serie de celdas, también ordenadas según el mismo principio, pero con sus caras orientadas en sentido contrario.

Una manera simple de superponer ambos planos sería haciendo coincidir celda con celda, pero esto permitiría el desplazamiento de un plano según el otro. Ante la posibilidad de que esto suceda, las abejas han encontrado la solución, intercalando las celdas de modo que no exista coincidencia entre ambos planos. A cada centro de una celda de uno de los planos corresponde un vértice de concurrencia de las paredes de la celda en el plano opuesto, tal como se muestra en la figura siguiente:

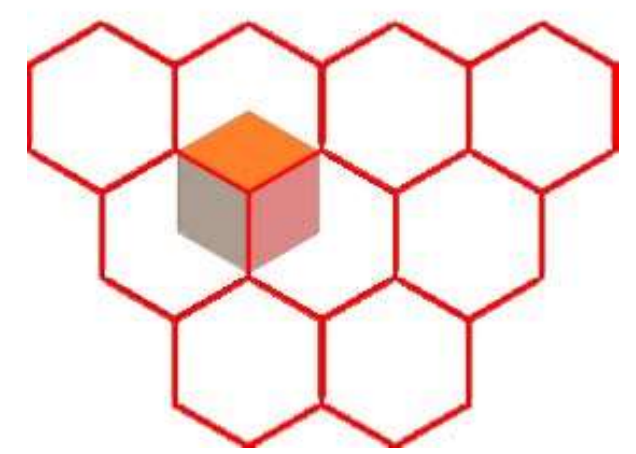

Ubicación alternada de las celdas en los dos planos superpuestos. Fuente: Producción propia

Como de igual manera, organizados así los dos planos, se mantendría el riesgo de desplazamiento, el fondo de las celdas no conforman un plano sino que se fracciona en tres rombos que se inclinan un cierto ángulo adosándose uno con otro en forma de pirámide.

Acá nos detendremos para exponer nuestra hipótesis, basada en los principios de equipartición del espacio 5 .
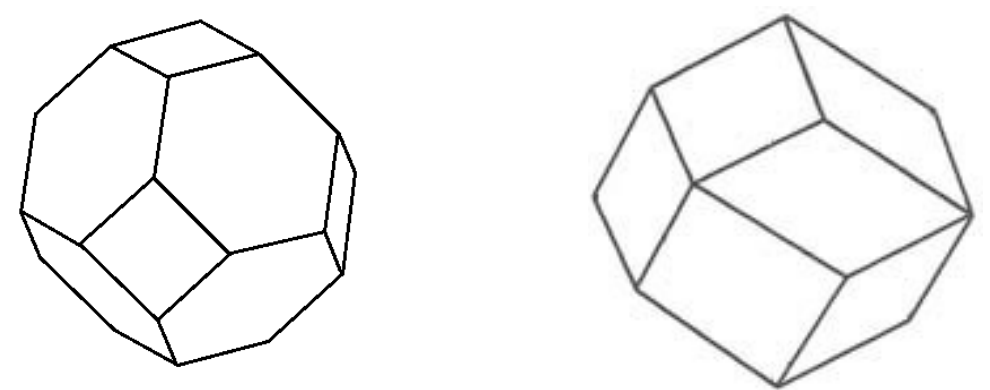

A la izquierda Poliedro de Lord Kelvin. A la derecha Dodecaedro rómbico. Fuente: Producción propia

Del mismo modo que en un espacio de dos dimensiones el triángulo, el cuadrado y el hexágono son las únicas tres figuras que lo macizan por adición de polígonos de una misma especie, en el espacio de tres dimensiones existen cinco poliedros que hacen lo propio: el hexaedro, o cubo, los prismas

\footnotetext{
${ }^{5}$ VEDOYA, Daniel E. y HERMIDA, María del C. (2013): PINCIPIOS BÁSICOS PARA LA ESCRUTURACIÓN DEL ESPACIO. Corrientes (Argentina): Ediciones del ITDAHu. ISBN 978-987-25052-7-1
} 
triangular y hexagonal, un poliedro semiregular arquimediano ${ }^{6}$, el tetrakaidecaedro o poliedro de Lord Kelvin, y un poliedro recíproco ${ }^{7}$, el dodecaedro rómbico.

La concurrencia de celdas de uno y otro plano se realiza precisamente aprovechando esta propiedad del dodecaedro rómbico de macizar el espacio de tres dimensiones.

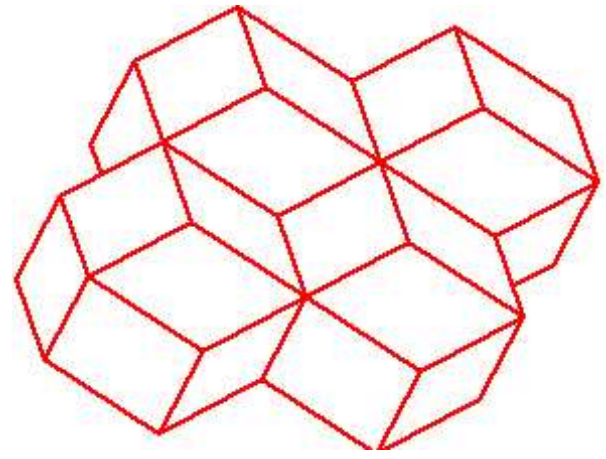

Ensamble de dodecaedros rómbicos - Fuente: Producción propia

El encastre de celdas de uno y otro plano toma una sección de cada dodecaedro para lograr un ensamble perfecto, sin dejar intersticios y lograr una continuidad espacial digna del más experto de los diseñadores espaciales.

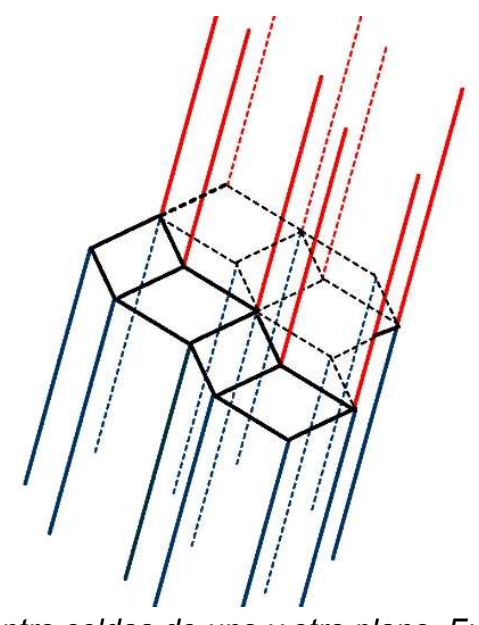

Detalle del encastre entre celdas de uno y otro plano. Fuente: Producción propia

\section{El color en la naturaleza}

En 1704, Newton identificó por primera vez la característica de 'color estructural' en el plumaje del pavo real.

El 'color estructural' se produce en los animales por la interacción de la luz con moléculas o nanoestructuras de un orden de magnitud similar a la longitud de onda de la luz.

Además de las brillantes plumas del pavo real que describiera Newton, el color estructural se encuentra también en las burbujas de jabón, en algunos charcos en el suelo, en el aceite derramado, etc.

No obstante, el azul es una pigmentación que se da en animales vertebrados y plantas sólo en ocasiones excepcionales.

${ }^{6}$ Los poliedros semiregulares arquimedianos se conocen así por haber sido Arquímedes de Siracusa quién los descubrió. Para más datos, consultar el libro de Vedoya y Hermida ya citado.

${ }^{7}$ El dodecaedro rómbico es un poliedro compuesto por doce rombos regulares que concurren alternativamente tres y cuatro por vértice. Es recíproco del cuboctaedro, un poliedro semiregular arquimediano que resulta de unir con segmentos los puntos medios de las aristas, tanto del hexaedro como del octaedro. Para más datos, consultar el libro de Vedoya y Hermida ya citado. 


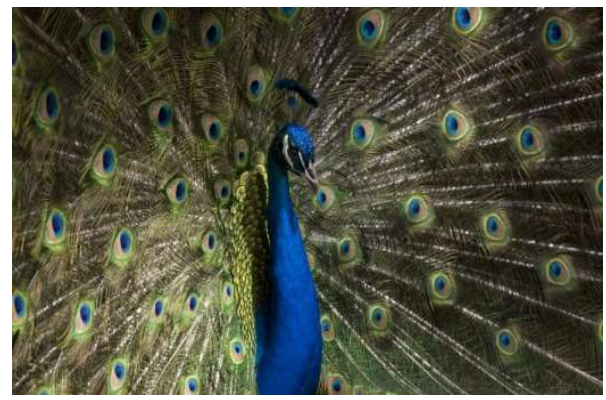

Pavo real

\section{Escarabajo}

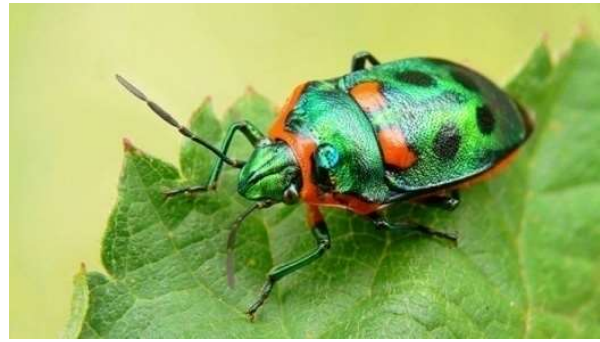

\section{Mariposas}

Tanto una hoja como el insecto están reflejando color verde

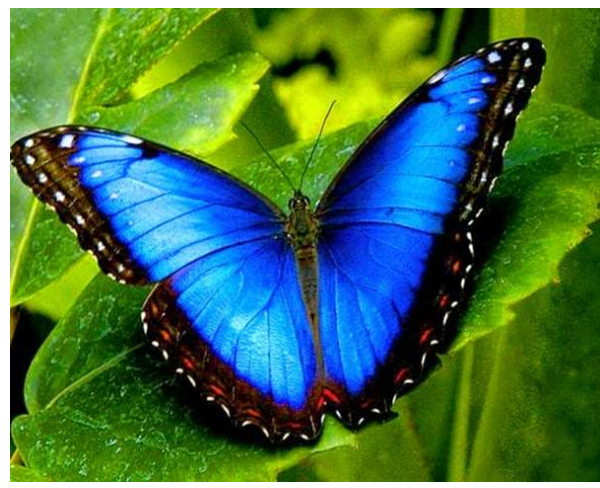

Se estima que existen 174250 especies de mariposas diurnas y nocturnas en el mundo, pero más diverso que el número de especies es la diversidad de patrones y coloración que en sus alas la evolución a "escrito".
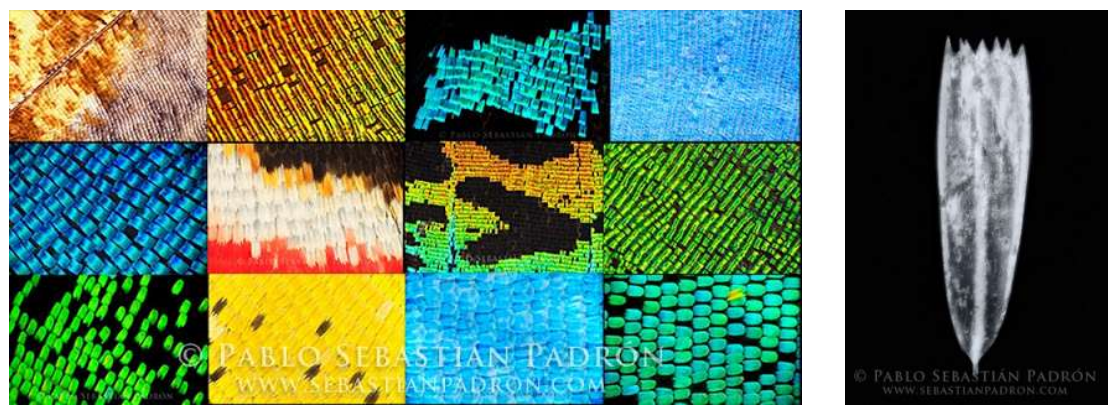

En las membranas expandidas la naturaleza escribe, como en una tablilla, la historia de las modificaciones de las especies. 


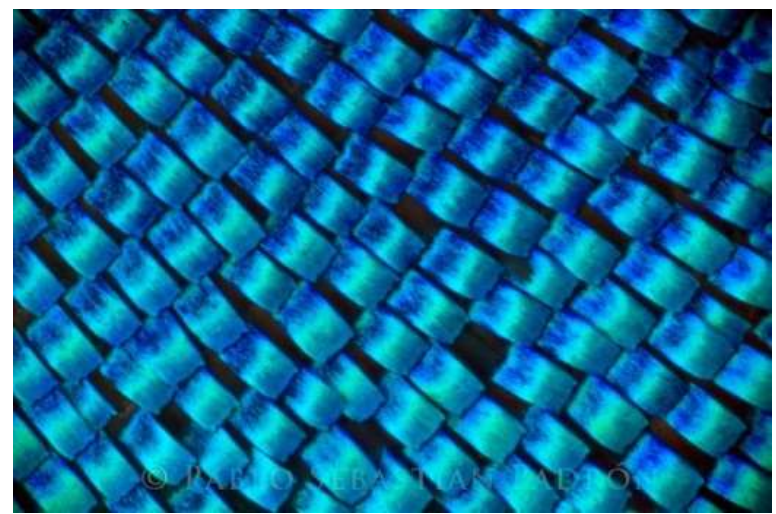

Detalle de las escamas en las ala de una mariposa del genero Prepona, la mayoría de la gente sólo ve un polvo que vuela, cuando sin mucho cuidado toca una mariposa.

Cada escama de las alas refracta la luz, conservando sólo aquellas longitudes de onda de color azul. Aunque todavía no hay respuestas concretas al misterio, algunos estudios sugieren que ocurre porque crear compuestos y superficies que reflejen la luz azul, en lugar de absorberla, requieren de sistemas más complejos y más energía como para que un organismo vivo pueda producirlos naturalmente.

Trucos como el del pavo real y las mariposas con su color estructural son una de las formas que tiene la naturaleza para hacernos ver ciertas tonalidades en organismos que, bajo otras circunstancias, no lo tendrían.

El color azul característico de las mariposas Morpho azules se debe a un fenómeno físico.

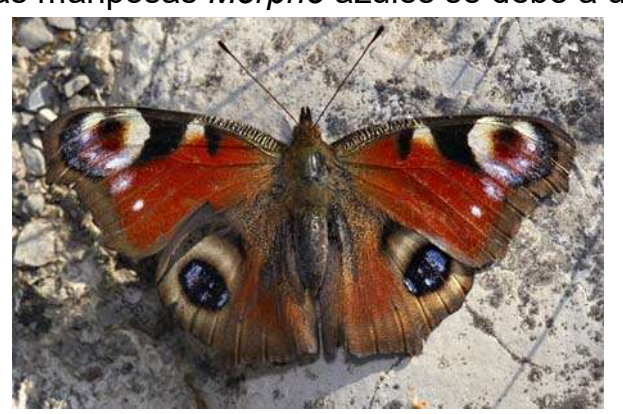

Colores de las alas de una mariposa según impactan en la vista
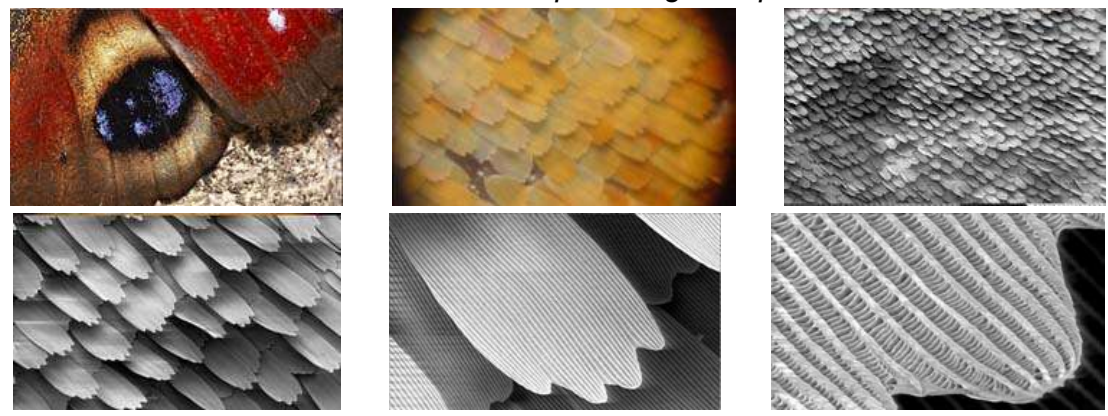

Detalle de los efectos del color de las alas en distintas raproximaciones con microscopio de barrido

\section{Las golondrinas}

Cuando dos ciudades tienen un acoplamiento, tanto por folklore o por el alma, ellas se declaran "ciudades hermanas".

Es el caso de los respectivos Jefes Comunales de dos ciudades: Goya, en la provincia de Corrientes (Argentina), y San Juan Capistrano, en California (EE. UU.), suscribiendo una declaración donde ambos municipios se constituían en ciudades hermanas.

Siempre y cada año, exactamente el mismo día, el día de Santo José, al mediodía, llegan las golondrinas en busca de los valles soleados de California. 
Cuando llega la primera bandada, cientos de golondrinas, desde hace 200 años, las campanas del viejo monasterio franciscano suenan mientras las golondrinas descienden a una altitud a la altura de las cabezas, reconociendo el terreno para placer de millares de turistas, entre ellos muchos niños que habían llegado para estar presentes para su llegada.

En verdad, han estado llegando para que los siglos y los milenios satisfagan fielmente su destino biológico: para vivir y reproducirse en climas benignos dentro de un esquema armonioso del control y de la regulación de insectos y de plagas. Ése es su destino en el plan integral de la naturaleza. Alimentándose de insectos, arañas, moscas, gusanos, la razón de su voracidad increíble es la siguiente: Para alimentarse, para vivir y reproducirse, y para almacenar la grasa en sus tejidos finos, que serán su combustible para el vuelo de vuelta.

Por siglos, el origen de la migración era desconocido en Capistrano y en Goya, hasta que en el actual siglo el origen de la migración podía ser determinado exactamente: Goya, Corrientes, la Argentina.
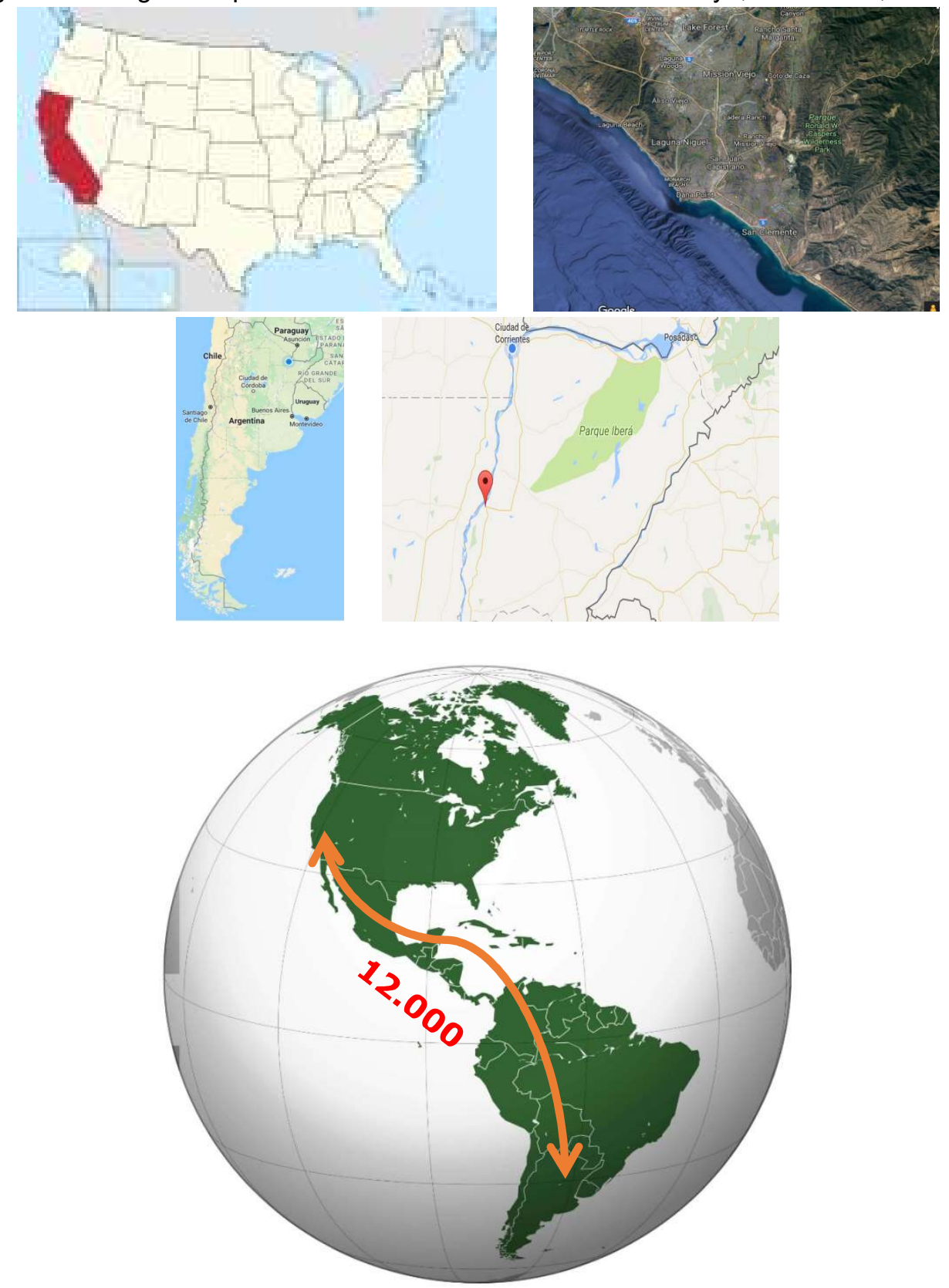

Se estudiaron sus vuelos y rutas y se tiene la certeza que terminan un vuelo fantástico de 12.000 kilómetros ( 7.500 millas) a Capistrano, y terminar los $24.000 \mathrm{~km}$, con un vuelo de vuelta, casi un vuelo completo alrededor de la Tierra. 
Debajo de los arcos romanos de los pasillos del monasterio franciscano de Capistrano, que tiene más de tres siglos de existencia, y plagadas de fechas históricas de la conquista española.

Con asombrosa exactitud, todos los años, el 24 de noviembre se las espera en Goya con una serie de festividades en su honor, junto al "Monumento de las Golondrinas", ubicado en Plaza San Martín, lugar preferido por estas avecillas para anidar.

En el amanecer del 18 de febrero las golondrinas dejan Goya en bandadas sucesivas, y llegan todas juntas a San Juan de Capistrano el 19 de marzo, llevándoles cubrir una distancia aproximada de 12.000 en exactamente treinta días.

Durante el vuelo, es decir, durante los treinta días que el viaje dura, ellas no comen ni beben, puesto que vuelan desde el amanecer a la puesta del sol para no perder tiempo.

Vuelan en una altitud de más de $2 \mathrm{~km}$ de la superficie terrestre (6.600 pies) para aprovecharse de las corrientes rápidas y favorables (vientos de la cola) y, además, porque en esa altitud evitan encontrarse con otros pájaros.

Su plan de vuelo dura quince horas diarias, en tramos de $450 \mathrm{~km}$, con una velocidad de $30 \mathrm{~km}$ (18 millas) por hora, aprovechándose siempre de los vientos.

El vuelo, que comienza en Goya, sigue por los valles de los ríos Paraná y Paraguay, hasta alcanzar el lago Mirin (entre el límite de Brasil y Bolivia), siguiendo las corrientes dinámicas que producen las masas grandes del aire del Sur que se mueven hacia el Ecuador.

Después de Mirin, cambian la ruta hacia el Oeste, en busca de los valles de los Andes y, en una travesía más, se dirigen al Ecuador, a una altitud más alta de vuelo para aprovecharse de las corrientes dinámicas que producen las grandes masas del aire que se mueven hacia el Polo Norte.

No cruzan los Andes hasta que han alcanzado el Golfo de México, y por el Yucatán buscan el Oeste y el Pacífico, para volar a lo largo de la orilla de Baja California y entrar en el valle de la orilla.

Ya en California, y después de la recepción del sonido de las campanas amistosas, se convierten en un factor decisivo en establecer un complejo equilibrio ambiental sano de enfermedades, regulando la cosecha de frutas, mientras acumulan las reservas de la grasa que será el combustible para el vuelo de vuelta.

\section{Combustible}

La grasa que acumulan en su cuerpo es equivalente al líquido combustible del tanque de un aeroplano.

Para su vuelo largo, igual con el que regresan $(12.000 \mathrm{~km}), 30$ viajes de $450 \mathrm{~km}$, los almacenes de cada golondrina tiene durante el suyo para 120 gramos de la grasa, que es un "tanque lleno", diría un piloto en el comando de un vuelo interurbano.

Es significativo que durante los 120 días se calcula que deben injerir 1.000 insectos diariamente, entre las moscas, las arañas y los gusanos.

Un detalle para apreciar la significación del número mencionado arriba para el equilibrio biológico y ambiental, es que una sola bandada de golondrinas consume, en una campaña, mil millones de insectos, un resultado que ningún insecticida puede hacerlo mejor, y todo sin producir el menos peligro a la fauna ni a la flora.

Es un trabajo inédito y excepcional, realizado igualmente tanto en Goya como en plantaciones de Capistrano.

Su "tanque lleno" de 120 gramos de grasa, no dura menos de $12.000 \mathrm{~km}$, en una velocidad de $30 \mathrm{kms}$ por hora, con una consumición de 0,01 gramo por kilómetro.

Un jet medio (un Boeing 737, por ejemplo) habría requerido 100 mil kilogramos de "JPI", un combustible especialmente para estos motores, que estiman costos de 60 centavos por litro.

Por lo tanto, al calcular y comparar gordo/calorías con JPI/calorías se encuentra que el cociente del PDM (el peso máximo de decolaje) del Boeing 737 y el de una golondrina es simplemente increíble.

El Boeing 737, con dos turbinas de consumición baja, quema 15 kilogramos (mínimo) por kilómetro, mientras que la golondrina quema solamente 0.01 gramo de grasa, lo que significa que la consumición del jet es un millón de veces mayor. 